Document downloaded from:

http://hdl.handle.net/10251/181068

This paper must be cited as:

Vega-Rodríguez, R.; Sendra, S.; Lloret, J.; Romero-Díaz, P.; García-Navas, JL. (2019). Low Cost LoRa based Network for Forest Fire Detection. IEEE. 177-184.

https://doi.org/10.1109/IOTSMS48152.2019.8939193

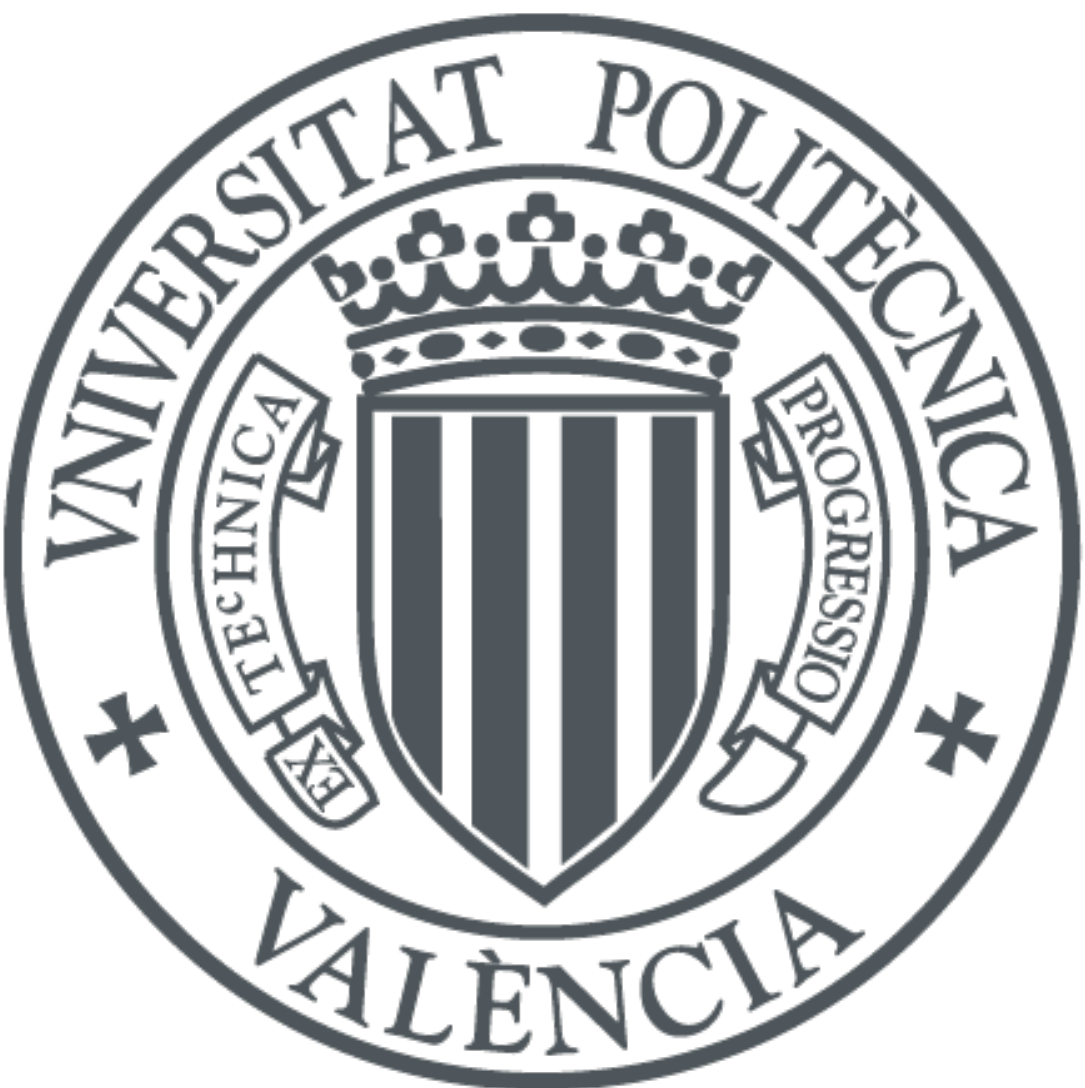

The final publication is available at

https://doi.org/10.1109/IOTSMS48152.2019.8939193

Copyright IEEE

Additional Information 


\title{
Low Cost LoRa based Network for Forest Fire Detection
}

\author{
Roberto Vega-Rodríguez ${ }^{1}$, Sandra Sendra ${ }^{1,2}$, Jaime Lloret ${ }^{2}$, Pablo Romero-Díaz ${ }^{1}$, Jose Luis Garcia-Navas² \\ ${ }^{1}$ Departamento de Teoría de la Señal, Telemática y Comunicaciones (TSTC) \\ Universidad de Granada \\ Granada, Spain \\ ${ }^{2}$ Instituto de Investigación para la Gestion Integrada de zonas Costeras (IGIC) \\ Universitat Politècnica de València \\ València, Spain \\ robertovr@correo.ugr.es, ssendra@ugr.es, jlloret@dcom.upv.es, pabloromerodiaz@ugr.es, jogarna3@teleco.upv.es
}

\begin{abstract}
Forest fires are one of the main environmental problems in the entire Mediterranean basin. In a context where low power and long-range networks (LPWAN) are increasingly common to the rise of Internet of Things (IoT) architecture, the interest in providing solutions to monitor scenarios and fire prevention based on these technologies is huge. This paper presents a low cost Long Range (LoRa) based network able to evaluate level of fire risk and the presence of a forest fire. The system is composed by a LoRa node and a set of sensors to measure the temperature, relative humidity, wind speed and $\mathrm{CO}_{2}$. The evaluation algorithm is based on the 3030-30 rule. Through website the users can see the parameters measured by nodes in real time. The system has been tested in a real environment and the results show that it is possible to cover a circular area of $1.1 \mathrm{~km}$ or radius.
\end{abstract}

Keywords-wireless sensor networks (WSN), LoRa, forest fire detection, Arduino, Dragino, The Think Networks (TTN).

\section{INTRODUCTION}

In the decade 2008-2018 there were an average of 12573 fires every year only in Spain. 4293 of them burned more than one hectare of forest [1]. The increase in the average annual temperature in the last quarter of the 20th century, depopulation of rural areas and changes in precipitations added to the desertification and the increase of the forest mass make the forest fire hazard indexes higher [2][3]. The prevention, control and study of fires are essential to prevent fires that devastate thousands of hectares, which imply a loss of economic and environmental resources, such as forests.

Currently, society is increasingly aware of the preservation of the natural environment. There is also an increase in the number of studies and scientific publications on this subject [4]. Although in Spain most fires are intentionally produced, those caused by human negligence or lightning are not negligible. The Mediterranean area is the area where negligence is the main cause of fire (50\%), above intentional, or lightning strikes. The Great Forest Fires (GIF), named for burning more than 500 forest hectares, is especially devastating. Figure 1 reports some statistical data on the number of fires and the area affected by them in recent years in Spain.

In a context in which Low Power Wide-Area Network (LPWAN), are increasingly common due to the rise of architectures based on the Internet of Things (IoT) [5], the interest in deepening in this type of protocols capable of providing monitoring solutions for scenarios such as fire risk analysis, where there is a large area to cover, it is very high.
Taking the autonomous community of Andalusia as an example, their different forest areas occupy more than 4.6 million hectares (more than $50 \%$ of the total surface). In such a wide area various method of control and prevention of forest fire are necessary. The most used systems in Spain are [6] [3].

- Fixed ground surveillance: based on direct visualization from advanced positions by operatives, panoramic photographs such as VIGIS or Ubifoc systems, infrared and optical cameras systems. The main disadvantage is the human factor and visibility problems related to the orography of the land and the type of vegetation present.

- Mobile land surveillance: The main objective is to complement the fixed terrestrial surveillance and eliminate blind spots. It is done by operational patrol. Some disadvantages are the high economic cost of the patrols, the discontinuity of their use and the small field of surveillance.

- Aerial surveillance: usually performed by helicopters and aircraft with GPS and infrared equipment. Systems based on unmanned vehicles are also being developed. The main disadvantage is its high cost.

- $\quad$ Spatial remote sensing: once the fire is produced, it is used to detect the main sources through the use of satellite images.

- Network of sensors: it is based on the connection of different types of sensors connected by means of a wireless network. The data is sent to a central device that processes the data.

In addition, the creation of risk maps and estimates based on data such as orography, vegetation type and state are used as means of prevention [3]. In the plan for the prevention and extinction of forest fires of the Andalusia Community (Plan INFOCA [3]), the following types of risk are considered:

- Structural risk: determined by the orography of the land and the characteristics of the vegetation.

- Weather risk: based on existing weather conditions.

- Risk of water stress: takes into account the stress conditions of the vegetation that are determined by the evolution of weather conditions. 
- Risk of fire frequency: calculated based on the number of fires that have occurred and their causality

Meteorological risk is a predictive and categorical index. The results refer to the future and are represented by categories or levels of risk. The indexes can be displayed in the form of maps (Haines index and probability of ignition) or tables (probability of ignition and the meteorological risk index).

The Haines index [3] is an indicator of atmospheric stability that allows knowing the risk of large fires. Evaluates the effect of atmospheric conditions on the vertical of the areas where the fire expansion occurs. The differences in temperature and humidity between the atmospheric layers of 750 and $950 \mathrm{hPa}$ allow the identification of factors that trigger large fires. The probability of ignition indicates the percentage probability that a cinder when falling on dead fine fuel burns it. The risk index is a categorization that expresses different levels (low, medium, high and extreme) of weather risk. It combines the probability of ignition with the wind speed and makes a correction with precipitation data. For the determination of the probability of large fires the "rule of 30" is used: values of temperature greater than $30^{\circ}$, a degree of relative humidity lower than $30 \%$, wind speed greater than $30 \mathrm{~km} / \mathrm{h}$ and absence of precipitation in the last 30 days. This risk index is the one that has been chosen for its implementation in our application.

By reference to IoT, understood as a network of physical devices that are connected to the Internet and capable of communicating with each other, it is breaking into different industries and markets. One of the applications is in the field of Smart Cities, to monitor different variables such as traffic, pollution, water systems, etc. Other industries of this type are [7]: smart grids, smart homes, healthcare, banking and logistics. Investment in this sector is growing, and as can be seen in Figure 2. Iit is estimated that by 2025 there are more than 75 billion IoT devices in the world [8].

As for the LPWAN, these are an emerging technology that offers a wide range of coverage (tens of kilometers), a very low consumption (years of autonomy) and a bandwidth of tens of kilobits per second. They use the ISM frequency range [9]. Due to the high demand, numerous LPWAN technologies have grown: LoRA, SigFox, RPMA, and many others in development such as 5G, NB-IoT, LTE Cat M1 [10] [11]. These features are suitable for Wireless Sensor Networks (WSN), which are networks that consist of different types of sensors used to continuously monitor a wide variety of environmental conditions.

The low price of sensors and the simplicity of the implementation of these technologies, even with services in

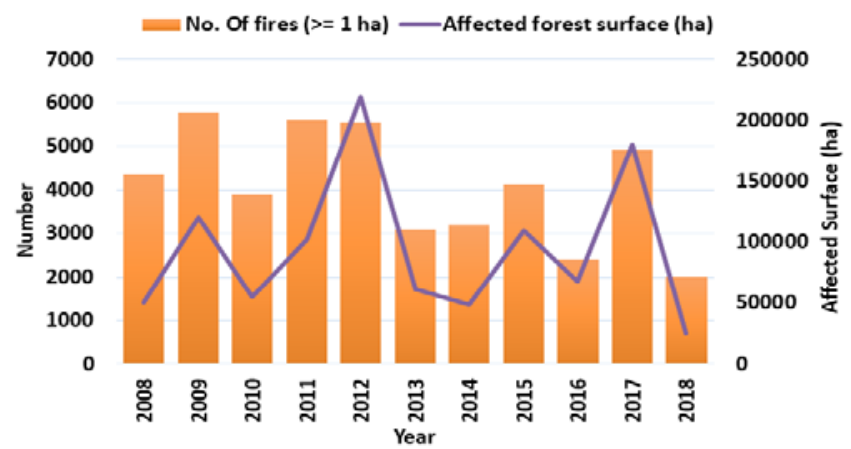

Fig. 1. Annual variation of registered fires and affected area in Spain [1]. the cloud or the web, make the development of monitoring networks based on LPWAN very attractive for infinity of projects.

Taking into account the importance of fast detection of forest fires and the evaluation of fire risk of these sensitive areas, this paper presents a low cost Long Range (LoRa) based network for forest fire detection which is able to determine level of fire risk of an area. The system is composed by an Arduino UNO board with a Dragino LoRa Shield and several sensors to measure the temperature, relative humidity, wind speed and $\mathrm{CO} 2$. The operation of our system is based on the 30-30-30 rule to determine the fire risk. We have also developed a web server and a web interface to visualize the results. The system has been tested in a real environment in terms of operation and network coverage.

The rest of this paper is structured as follows. Section II presents some related work. The proposed system and the network architecture are explained in Section III. Section IV presents the web server and the web interface developed to see the data. Section V describes the testbench and the results obtained. Finally, Section VI draws the main conclusions and future work.

\section{RELATED WORK}

This section presents the most important WSNs implementations for forest fire detection. We have classified them by the wireless technology used.

Perez-Garrancho et al. [12] propose a mobile low cost system for environmental monitoring in emergency situations. The system is composed by a sensor node, installed on the citizens' private vehicles, which is connected to a smartphone via Bluetooth to take advantage of the $3 \mathrm{G} /$ 4G connectivity. 3G / 4G connectivity is used to send alarm messages, through Internet, to a central database. They conclude that the system can be very useful to determine possible evacuation routes to rescue stranded citizens, in emergency situations, such as forest fires.

Hariyawan et al. [13] perform a system for Forest Fire Detection using WSN with multiple sensor nodes. Each node contained a microcontroller, transmitter/receiver and three sensors. They used a method of measurement based on parameters such as temperature, flame, the levels of methane, hydrocarbons, and $\mathrm{CO} 2$ in some forest area and the combustion of peat in a simulator. From these measurements they established some fire hazard indexes that makes possible to prevent and detect forest fires. They used the Wireless Data Transceiver KYL 500S to transmit and receive serial data to implement the project.

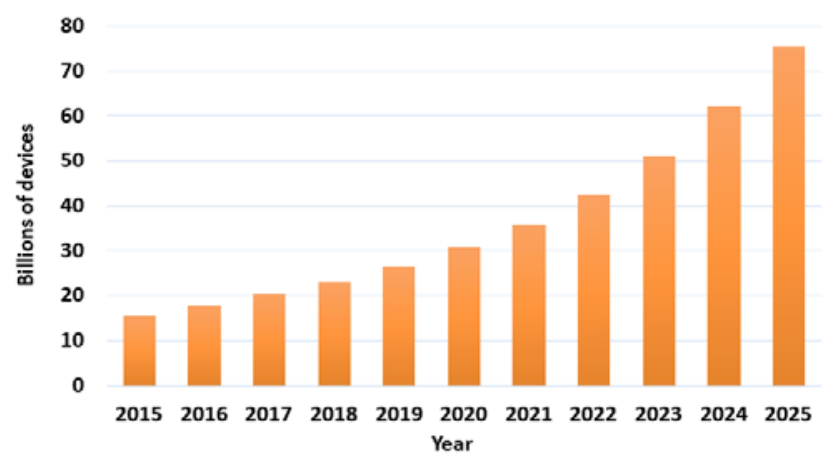

Fig. 2. Estimation of connected IoT devices per year in billions [8]. 
Liyang Yu et al. [14] propose a WSN paradigm for realtime forest fire detection such a better alternative to satellitebased monitoring. Their goal is to detect and predict forest fire promptly and accurately in order to minimize the loss of forests, wild animals, and people in the forest fire. In their proposal, a large number of sensor nodes collect measured data and send to their respective cluster nodes that collaboratively process the data by constructing a neural network. They applied a neural network method to process the in-network data. The neural network produce weather index, which measures the likelihood for the weather to cause a fire. Cluster headers send weather indexes to a manager node that concludes the forest fire danger rate based on received weather indexes and some other factors.

In [15], Abdullah et al. discusses a new category of compact, easily deployable and energy efficient approach to sensor nodes for the continued monitoring of forest environments as well as the early detection of fires in their infancy based on a combination of sensory inputs. This work was undertaken as a part of the Advanced Fire Fighting (AF3) Project. In this paper a Low Power Wireless Ground Sensor Network (LPWGSN), that provides near-real-time environmental monitoring capabilities, was developed. The LPWGSN deals with the early detection aspect as well as monitoring fire progress. LPWGSN employ a wide set of sensors as well as energy harvesting, signal processing, transmission and reception components for an enhanced network power autonomy as well as maximum area coverage with lower overall cost. The designed nodes were tested during a real-life firefighting trial in Greece where the overall results of the LPWGSN were positive and encouraging. The WSN was able to successfully capture environmental parameters and upload the data to the AF3 Ingestion Server for post processing.

Lloret et al. [16] show all the steps followed to perform a wireless multisensor network, based on a Linksys WRT54GL router, which mixes sensors with IP cameras in a wireless network in order to detect and verify fire in wide extension fields of rural, agricultural and forest using the 802.11g Wireless Local Area Network (WLAN) technology. When multisensor detects a fire, it sends a sensor alarm through the wireless network to a central server. The central server selects the closest wireless cameras to the multisensor and sends them a message in order to receive real-time images from the zone. It allows corroborating the existence of a fire and avoiding false alarms. They show the test performance given by a test bench formed by four wireless IP cameras in several situations and the energy consumed when they are transmitting. The bandwidth consumption measurements given by the test bench show that the system supports up to 34 wireless IP cameras in each Access Point, and also show that the design is scalable.

Hristov et al. [17] discuss and present two different solutions for early detection of forest fires. The first one involves the use of unmanned aerial vehicles (UAVs) with specialized cameras. They present and analyzed different scenarios for the possible use of the drones for forest fire detection. The study comments the possibility of using a combination between a fixed-wind and a rotary-wing UAVs.
The second solution is based on the possibilities for development of systems for early forest fire detection using LoRaWAN sensor networks.

\section{SYSTEM DESCRIPTION}

This section explains the proposed system and the network architecture, as well as the hardware and sensors used to develop our system.

\section{A. Architecture}

The network architecture used in this system follows the LoRa specifications, i.e., a set of sensors placed in the scenario, a Gateway which collects the nodes' information and a data base used to feed the web application to inform users. So, to develop our network it is required to carry out:

- The design and development of the end nodes capable of monitoring environmental variables and sending information using the LoRaWAN class A specification [9] which present the lowest power consumption. It should also be economic.

- LoRa Gateway configuration. It is used to collect data from the LoRa nodes and forward them to a server for storing and/or processing. The model used is manufactured by The Things Network. It contains a $\mathrm{Wi}-\mathrm{Fi}$ and LoRa connection. It is powered by an electric socket although it can be powered by USB-C interface. Finally, it has an omnidirectional antenna capable of listening up to 8 LoRaWAN channels.

- Network storage server: It is used the free online service provided by The Things Network (TTN) which will provide us with the necessary tools for collecting and storing the data with the minimum cost.

- Data base (DB): our proposed system uses the DB that TTN offers.

- Creation of a web application: two programs have been developed. The first one is in charge of performing the requests to the $\mathrm{DB}$ and will be in charge of translating the information into an appropriate format. The second program will process this information according to the requirements established by the method of prevention in large forest fires, the 30-30-30 rule.

As a summary, our system is composed by a set of LoRa nodes that collect information on relative humidity, temperature, wind speed and concentration of $\mathrm{CO}_{2}$. These values will be sent to the TTN server through the LoRa gateway to finally be stored in the DB. The application server will perform requests to the $\mathrm{DB}$ and after processing the values, they will graphically representation on a website. Figure 3 shows the network architecture and the data flow followed by the information gathered

\section{B. LoRa node}

The LoRa node or end device will be responsible for collecting environmental information in the natural environment. 


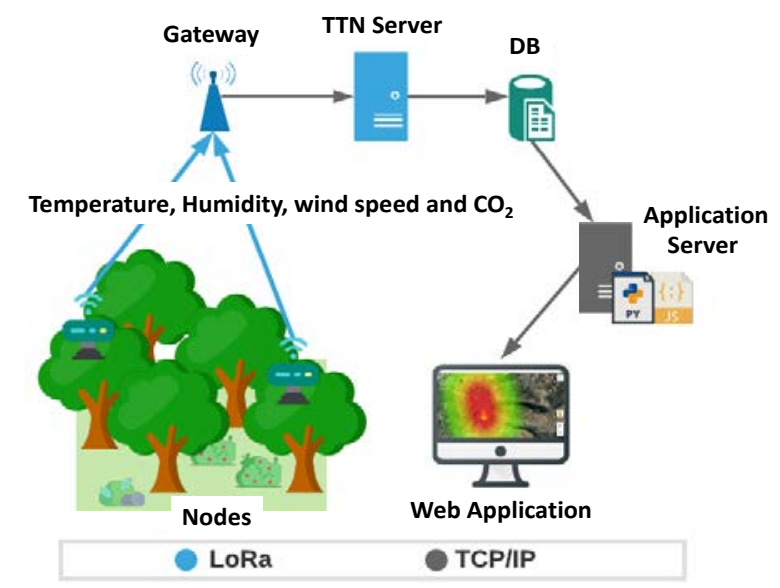

Fig. 3. Network architecture

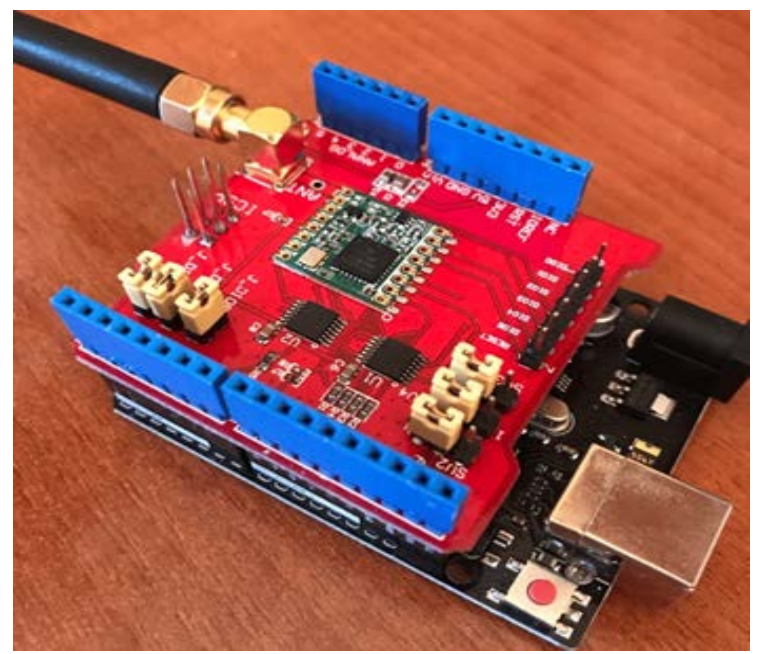

Fig. 5. Dragino LoRa Shield coupled with the Arduino UNO module.

As we mentioned before, the risk index calculation used in this system is the so-called 30-30-30 rule, the node will be able to collect information on temperature, relative humidity and wind speed. To strictly comply with this rule, we should also collect information about rainfall in the previous thirty days. This issue can be solved adding a pluviometer or combining our data with the data provided by the National meteorological agency.

It is important to remark that the 30-30-30 rule which would consider the fact of considering the rainfall is not the most efficient method since a forest fire sometimes depends of the area it is placed and its topography. In fact, according to [18], only the compliance of the limit values in two variables is enough to predict around the $70 \%$ of the large forest fires where considering the wind speed is especially relevant. On the contrary, the compliance of all the variables, it only correlated with the $40 \%$ of the large fires that happened in the 2007-2016 period.

The LoRa node has been implemented considering its power consumption since the final version of this system will be powered by solar panels and batteries. The different blocks that compose the LoRa node are shown in Figure 4.

The main board that composes our system is an Arduino Uno Rev3 module, which has a Microchip ATmega328P microcontroller and it is used to process the data. It has 14

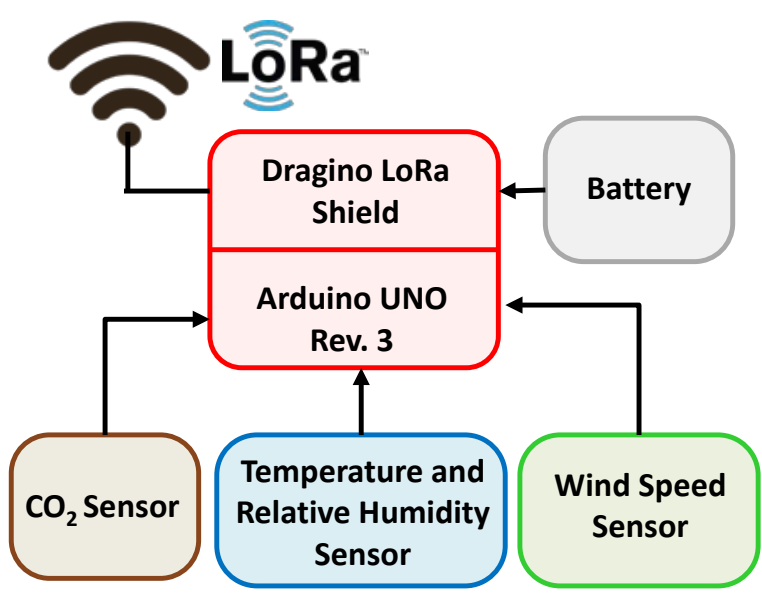

Fig. 4. Modelo de bloques de los componentes de la mota.

digital inputs/outputs and 6 of them can be used for PWM outputs. It also has 6 analog inputs, a $16 \mathrm{MHz}$ oscillator and $32 \mathrm{~KB}$ of Flash Memory, $2 \mathrm{~KB}$ of SRAM and $1 \mathrm{~KB}$ of EEPROM.

We will also use the Dragino LoRa Shield board compatible with our Arduino development board that incorporates the RFM95W transceiver with the SX1276 chip from Semtech. It will allow us the use of LoRaWAN modulation to establish the communication between devices. Our model is factory configured to work in the $868 \mathrm{MHz}$ frequency band.

It works on the three channels that LoRaWAN specification establishes. As we can see in Figure 5, both the Dragino LoRa Shield and the Ardunino UNO Module are coupled. We also incorporate $868 \mathrm{MHz}$ external antenna which uses a SMA connector.

\section{Sensors}

In order to collect data from the environment, our LoRa node uses three different sensors.

To measure the temperature and relative humidity, it is used a DHT11 sensor. It is coupled to a small 8-bit microcontroller which has been calibrated at the factory. The temperature working range is between $0{ }^{\circ} \mathrm{C}$ to $50{ }^{\circ} \mathrm{C}$ with a precision of $\pm 2{ }^{\circ} \mathrm{C}$ and the relative humidity working range comes from $20 \%$ to $90 \%$ with a precision of $\pm 5 \%$.

The sensor used for collecting $\mathrm{CO}_{2}$ concentration is the MQ135 which also comes coupled to a small microcontroller and is able to give the output values in both digital and analogical format. This sensor is capable of detecting NH3, $\mathrm{NOx}$, different kinds of alcohol, benzene, smoke and $\mathrm{CO}_{2}$. The sensor operation is based on a chemical reaction that takes place inside it through a resistance that heats up. The measured value is proportional to the resistive value of this resistance measured at the output of the circuit after driving through the load resistance.

Finally, we will use a low cost anemometer designed by using a small DC electric motor used as a generator and a weather vane designed with the CAD 3D SolidWorks design program. The 3D model (see Fig. 6a) design, the printed parts of the weather vane (see Fig. 6b) and the final result of or device (see Fig. 6c) is shown in Figure 6. The connection diagram of our node is shown in Figure 7. 


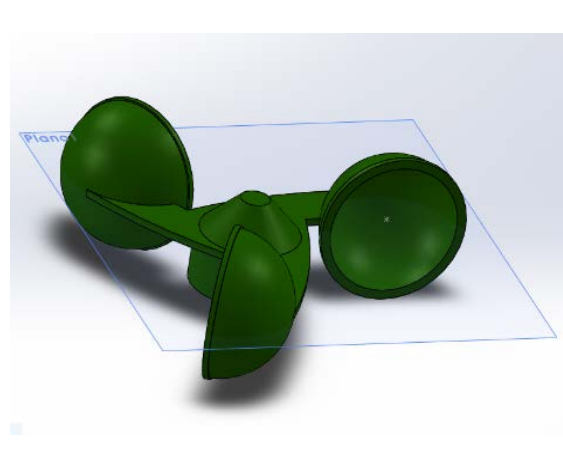

a)

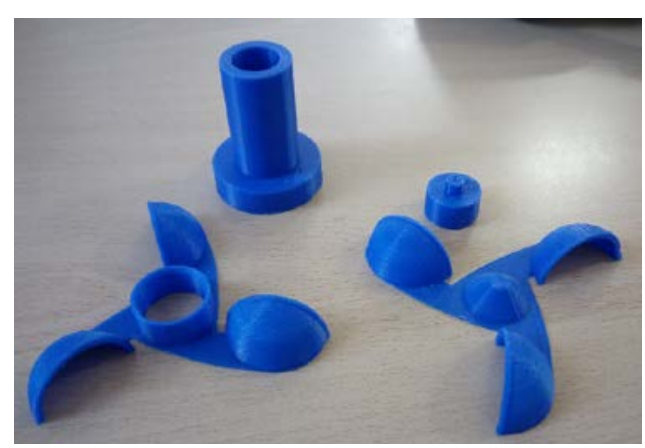

b)

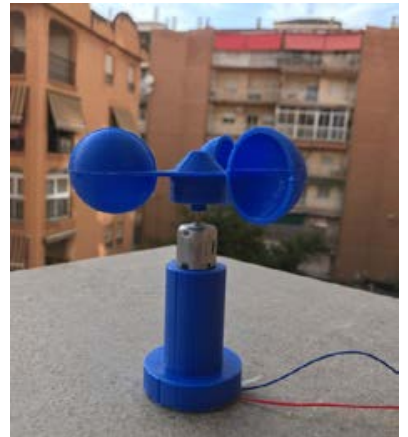

c)

Fig. 6. Weather vane design and its final aspect.

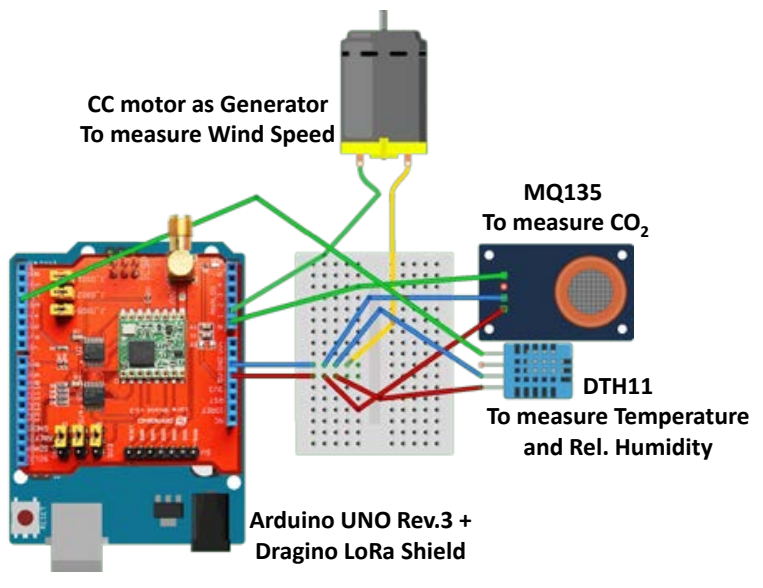

Fig. 7. Node totally assembed

\section{APPLICATION SERVER DESIGN}

The application server is an HTTP web server. Specifically, we use the Apache open source server version 2.0. The web server contains a program that will make requests to the DB implemented in TTN and modify the data to transform them into a readable format by the program implemented on the web also hosted on the Apache server. It will interpret these data. This section presents the web server operation and configuration and the web interface developed to allow users to see the data in real time.

\section{A. Web server}

The web server also hosts a web interface which implements a written script in the interpreted and oriented to objects programming language JavaScript, i.e., our script is within the HTML language code for web page development. The script has been made using the Google Maps API which allows working with maps and satellite images owned by the company Google, as well as being able to paint markers, information windows, polygons, heat maps, etc. This script consists of two main functions:

- $\quad$ initMap ( ): This function is responsible for initializing and painting the map. It will define the initial coordinates where the map will be loaded, in addition to the zoom and the type of map (i.e. satellite, street, hybrid or orographic images). The data in the "data.json" file created by the Python program is saved in a variable. This function also create a library of which we will use later to create several types of bookmarks based on the data of the file created by the Python program. For a better compression of the function a flow diagram is shown in Figure 8.
- eqfeed callback(results): This function creates a file where the coordinates of the nodes that exceed the values imposed by the 30-30-30 rule will be saved. It gets the values of the JSON objects from the "data.json" file. It defines a marker that indicates fire if the value of the $\mathrm{CO}_{2}$ concentration exceeds the 700 ppm threshold and displays an alert by screen. This function also defines the information windows that will be displayed by clicking on the markers and their format. Finally, the function is in charge of painting both the markers and the heat map, in case the defined thresholds have been exceeded. The flow diagram of this function is shown in Figure 9.

At the end of the script, the JavaScript function "setInterval (function, time)" is used. It allows periodically calling a function in the interval of milliseconds we define in the input variable of the function called "time". We will use this function to call the function "initMap" and thus refresh the data of our map every 5 minutes (300000 milliseconds) to have the up-to-date data.

\section{B. Web interface}

Figure 11 shows the web interface developed to visualize the values measured by each node. Results are show in real time and are updated each 5 minutes. In the bottom of the web site, we can see a legend with the icons used to mark the presence of fire (a flame, or not (a green sheet, the heat maps (a map, and additional information of nodes (a blue circle, $i$ ). As Figure 10 shows the icon of green sheet will be shown when $\mathrm{CO}_{2}$ concentration is below the threshold while the flame will be shown when the registered value is higher than the specified threshold. The heat areas are shown when the values determined by the 30-30-30 rule have been exceeded. Clicking on each icon, a new dialog square appears with the values of the environmental variables measured. When the threshold of fire detection is exceeded, the system will show an alert showing the geographical coordinates of the node that generated the alarm (see Figure 11). Accepting the alert, we can access to the map and see the icon of a flame which indicates the position of node and the presence of fire.

Figure 12 shows a scenario where 2 nodes are shown. We can see the heat map which indicates that the values determined by the 30-30-30 rule have been exceeded. Additionally, one of these nodes has detected a concentration of $\mathrm{CO}_{2}$ of $850 \mathrm{ppm}$, a temperature higher than $30{ }^{\circ} \mathrm{C}$ with a relative humidity lower than $30 \%$ and a wind speed of 35 $\mathrm{km} / \mathrm{h}$. 


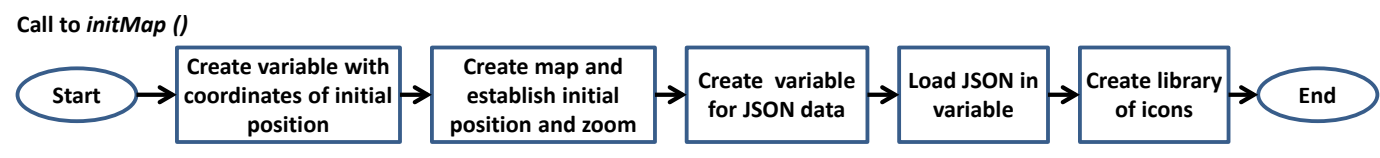

Fig. 8. Diagrama de flujo de la función initMap.

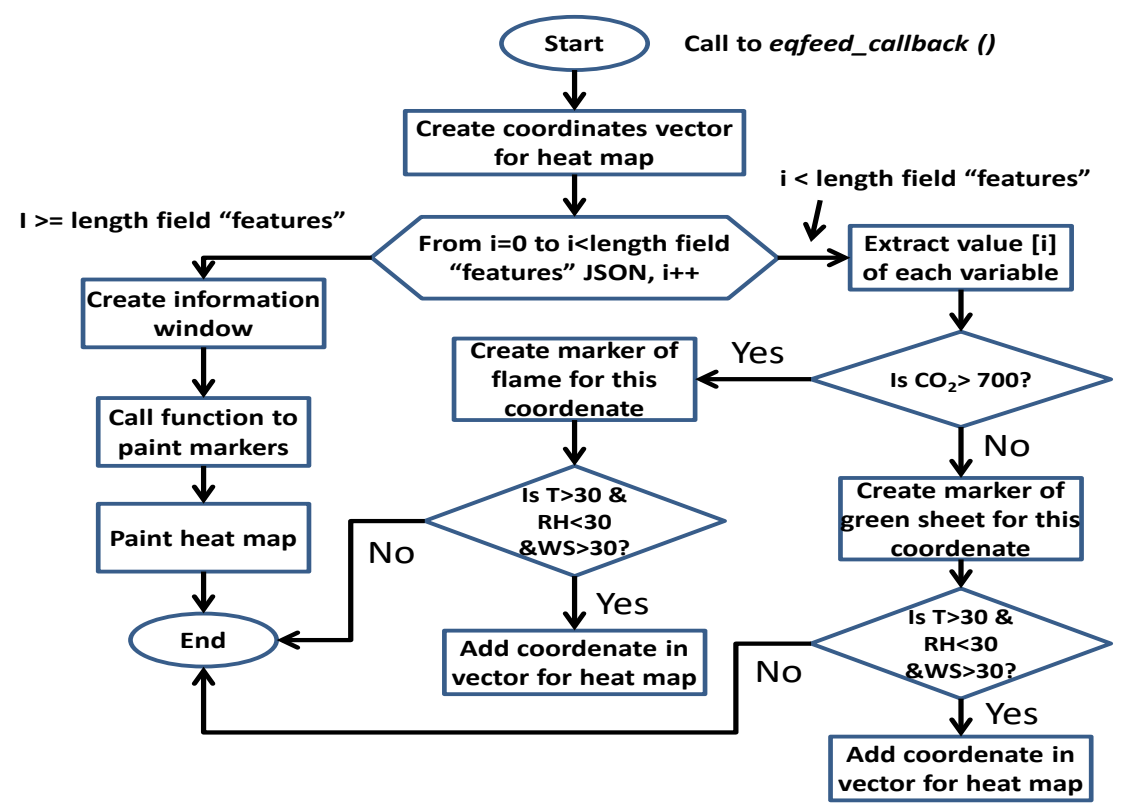

Fig. 9. Diagrama de flujo de la función eqfeed_callback.

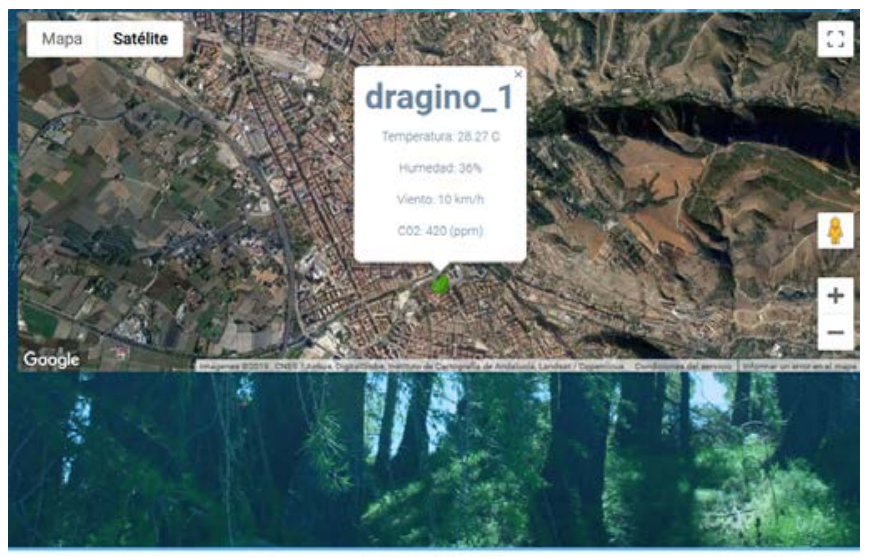

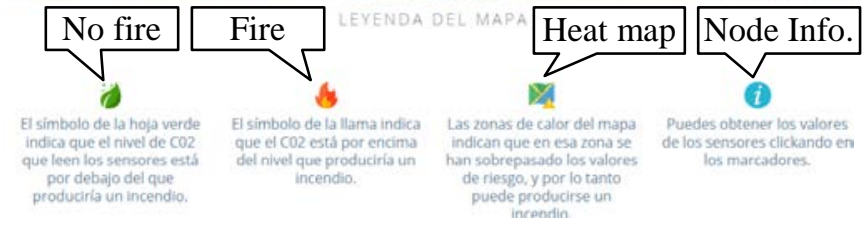

Fig. 10. Web page of system showing real time data of the LoRa node.

\section{TESTBEnCH AND REsults}

To finalize the development of our low cost LoRa based network for forest fire detection, it is important to check the network performance, wireless coverage [19] and the correct operation of the sensors. So, this section presents the test bench of our system in terms of coverage and the results of the included sensors in the node. The tests have been performed in a real environment.

\section{A. LoRa coverage in rural environment}

To perform the coverage test, we used the designed node (see Figure 13) connected to the Gateway and the TTN
Se ha declarado un incendio en: (36.740025, -3.4066669999999704)

\section{A fire has been detected in:}

Aceptar

Fig. 11. Warning that appears on the screen when a fire is detected

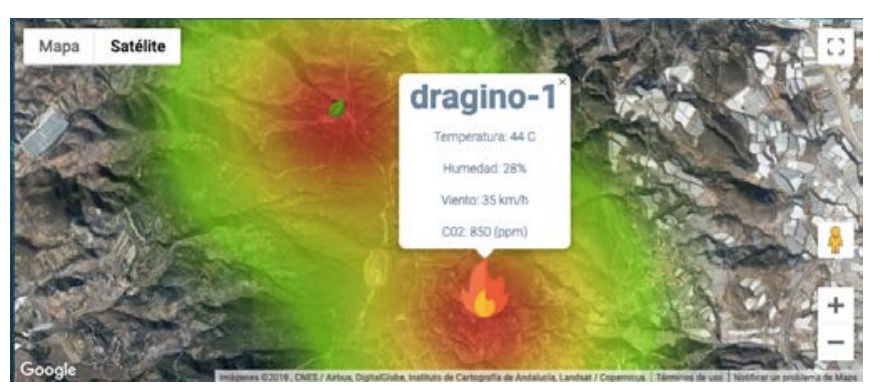

Fig. 12. Web site that shows fire risk and registers a fire alarm in a node

Mapper application to locate the node. Subsequently, the data provided by the application is represented in the Google Earth program. The selected scenario to carry out the tests is a rural environment formed by vegetation zones. The gateway is located in an elevated area where the fixed surveillance services are usually located (See Figure 14).

The coverage measures are taken transiting the forest roads enabled for this purpose. The SF $=7$ has been used because it is the configuration that would offer us the results in the worst possible scenario. Figure 15 shows the RSSI results obtained by the TTN Mapper application as a function of the distance to the Gateway while Figure 16 
shows the RSSI values positioned on a real image of the natural environment under study. The RSSI values are obtained based on the distance to the Gateway, the red colors being the points with the best RSSI and the green points the points with an RSSI less than $-110 \mathrm{dBm}$. As we can see, a LoRa network like the one implemented in this proposal is capable of covering an area of approximately 314 ha $(3,141,592.65 \mathrm{~m} 2)$ which is equivalent to having a circular area of $1 \mathrm{~km}$ radius. The LoRa technology would allow us to cover areas of up to $4 \mathrm{~km}$ [20] in scenarios where we have no obstacles. However, the scenario analyzed shows large plant masses that cause a large dispersion in the signal. Even so, we observed coverage ranges of $1 \mathrm{~km}$, a very interesting value to consider, if we compare with the deployment of a WSN based on WiFi.

\section{B. Data from sensors}

To be sure the node is operative, we check the correct operation of each device. Measurements were performed near to a road in Granada (Spain) during 11 hours. The system has been configured to take a measurement each 28 minutes.

Figure 17 shows the values of temperature. As we can see the maximum temperature $\left(28.7^{\circ} \mathrm{C}\right)$ has been registered around 17:10 hours. This value decreases from 22:17 hours reaching values of $24.3^{\circ} \mathrm{C}$. The relative humidity (see Figure 18) decreases as the temperature increases throughout the day reaching the minimum value (22\%) at $18: 34$, with a value of $22 \%$. When the night comes, the relative humidity value increases again.

Regarding to the wind speed (see Figure 19), we also register the maximum values in the afternoon, decreasing considerably at night.

Finally, Figure 20 shows the $\mathrm{CO}_{2}$ concentration values recorded by our node. The 2 peaks with the highest $\mathrm{CO}_{2}$ levels correspond to the work in and out schedule of most of the citizens of Granada. This makes us think that the increase in traffic in the city considerably increases the levels of $\mathrm{CO}_{2}$ and other particles in the air of our cities. Extrapolating these results to a rural scenario, we can conclude that using our low cost LoRa based node it is possible to detect the presence of a fire and visualize areas of high risk of fire in real time, seeing their evolution over time.

\section{CONCLUSION AND FUTURE WORK}

When a forest fire burns the natural landscapes that surround us, it not only has direct impact on the landscape, flora and fauna that live there, but also the risk of erosion of the earth increases, large amounts of $\mathrm{CO} 2$ are released into the atmosphere and can even affect the citizens themselves. For these reasons, it is important to have a system capable of detecting the presence of a fire at a certain point and it is also important to be able to determine the level of fire risk in an area.

Therefore, in this paper, we have presented a low cost LoRa based network for forest fire detection. The system is based on a set of nodes composed by sensors to measure the temperature, relative humidity, wind speed and $\mathrm{CO} 2$ to evaluate the level of fire risk and the presence of a forest fire. The data are sent to a server in charge of showing them in real time over a map (through a website) which locates the node and permits monitoring the data per node. The system has been tested in a real environment, showing very interesting results and range coverage of $1.1 \mathrm{~km}$.

As future work, we would like to test our system in a wider area considering additional parameters such as rainfall historical data from previous experiences and combine the operation of our system with drones. Finally, our system could be adapted to other applications such as the precision horticulture.

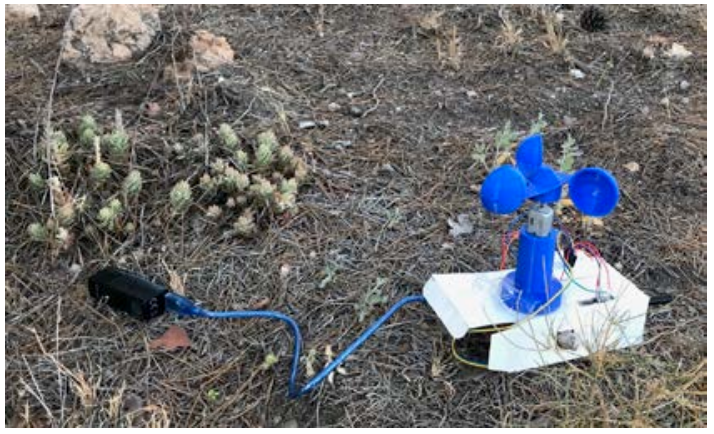

Fig. 13. Mota tomando datos en el terreno

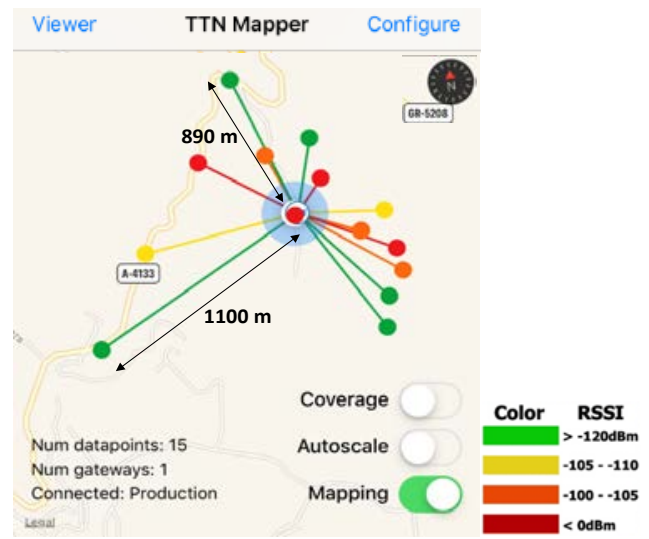

Fig. 15. Coverage results measured with TTN Mapper.

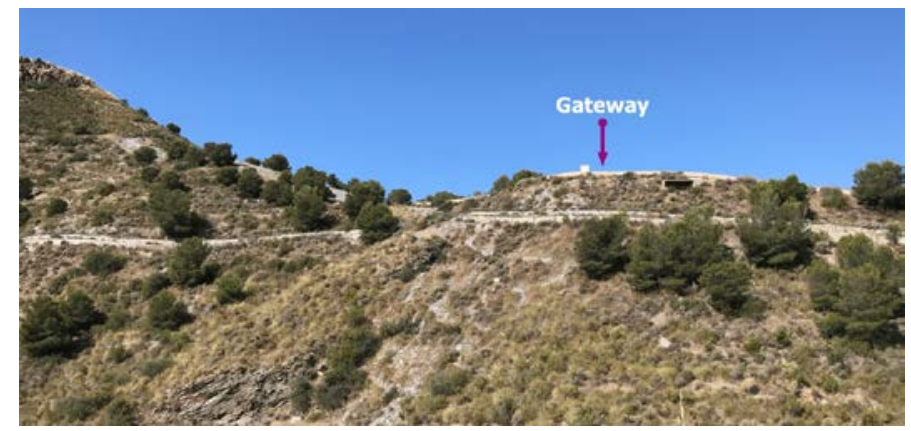

Fig. 14. Posición del gateway en el test de cobertura completamente rural.

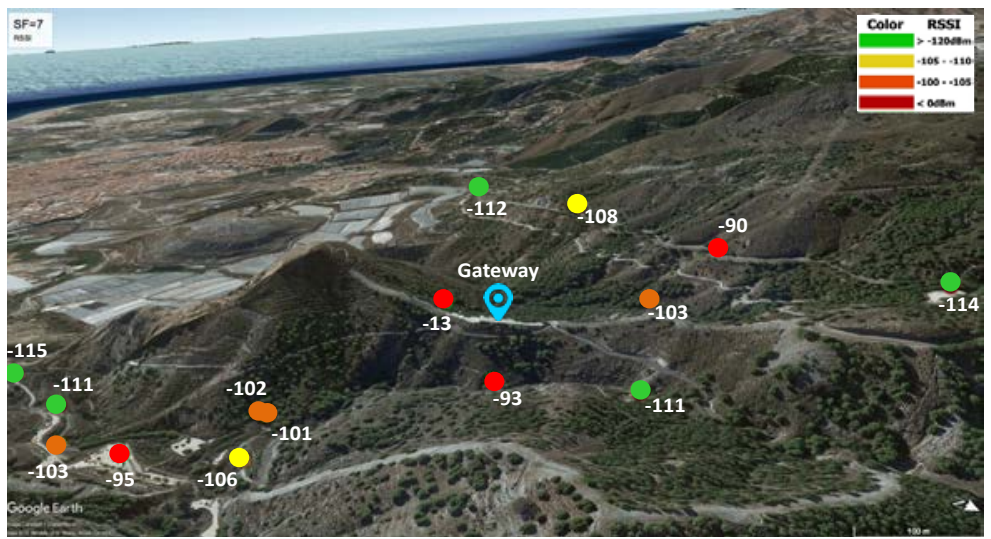

Fig. 16. Data placed over the real scenarion. 


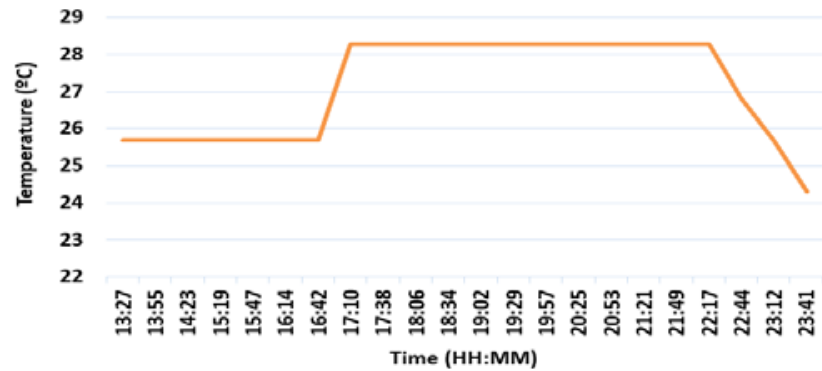

Fig. 17. Temperature.

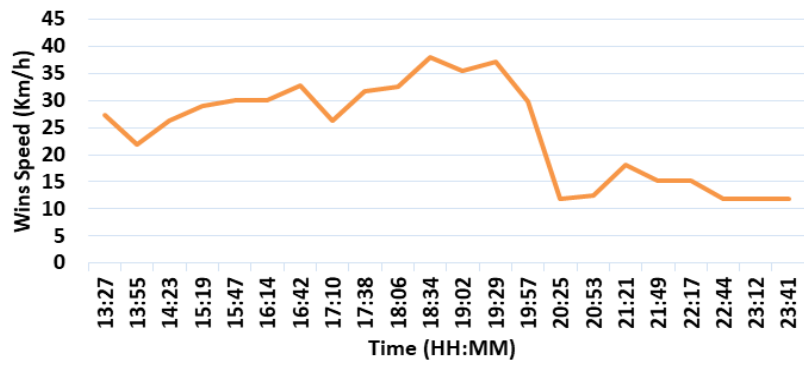

Fig. 19. Wind Speed.

\section{ACKNOWLEDGMENT}

This work has been partially supported by the "Ministerio de Ciencia, Innovación y Universidades" through the "Ayudas para la adquisición de equipamiento científicotécnico, Subprograma estatal de infraestructuras de investigación y equipamiento científico-técnico (plan Estatal $\mathrm{I}+\mathrm{D}+\mathrm{i}$ 2017-2020)" (project EQC2018-004988-P) and through the Research Contracts of Youth Employment of the University of Granada, through its operative program of Youth Guarantee of the Regional Government of Andalusia and the European Social Fund.

\section{REFERENCES}

[1] Spain in numbers 2018 (Original: “España en cifras 2018”). INE. Available at: https://www.ine.es/prodyser/espa_cifras/2018/ [Last access: June 29, 2019]

[2] M. Turco, S Jerez, F.J. Doblas-Reyes, A. AghaKouchak, M. C. Llasat and, A. Provenzale. "Skilful forecasting of global fire activity using seasonal climate predictions”, Nature communications 2018, vol. 9, no 1 , p. 2718

[3] INFOCA Plan, analysis of risks 2017, (Original title: "Plan INFOCA, análisis de riesgos”). Ministry of agriculture, livestock, fisheries and sustainable development. Available at: https://www.juntadeandalucia.es/medioambiente/web/Bloques_Temat icos/Patrimonio_Natural._Uso_Y_Gestion/Montes/Incendios_Foresta les/plan_infoca/Cap05_analisis_riesgo.pdf [Last access: Jun 29,2019]

[4] R. Seidl, D. Thom, M. Kautz, D. Martin-Benito, M. Peltoniemi, et al "Forest disturbances under climate change". Nature climate change, 2017, vol. 7, No. 6, pp.395.

[5] K. Lasse Lueth, "State of the IoT 2018: Number of IoT devices now at 7B - Market accelerating". Available at: https://iotanalytics.com/state-of-the-iot-update-q1-q2-2018-number-of-iotdevices-now-7b/ [Last access: June 29, 2019].

[6] C. Molina, J.Solana and, G.Herrero. "Sistemas de detección de incendios forestales en España”. Revista Montes, 2009, pp.89-95.

[7] D. Minoli, K. Sohraby and, B. Occhiogrosso. "IoT considerations, requirements, and architectures for smart buildings-Energy optimization and next-generation building management systems". IEEE Internet of Things Journal, 2017, vol. 4, no. 1, pp. 269-283.

[8] A. Nordrum, "Popular Internet of Things Forecast of 50 Billion Devices by 2020 Is Outdated”. (online article). IEEE Spectrum's General Technology Blog. 18 Aug 2016. Available at: https://spectrum.ieee.org/tech-talk/telecom/internet/popular-internetof-things-forecast-of-50-billion-devices-by-2020-is-outdated [Last access: June 29, 2019]

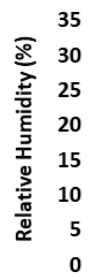

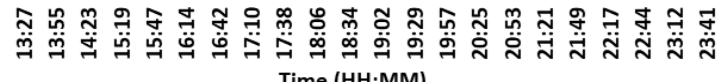

Fig. 18. Relative Humidity.

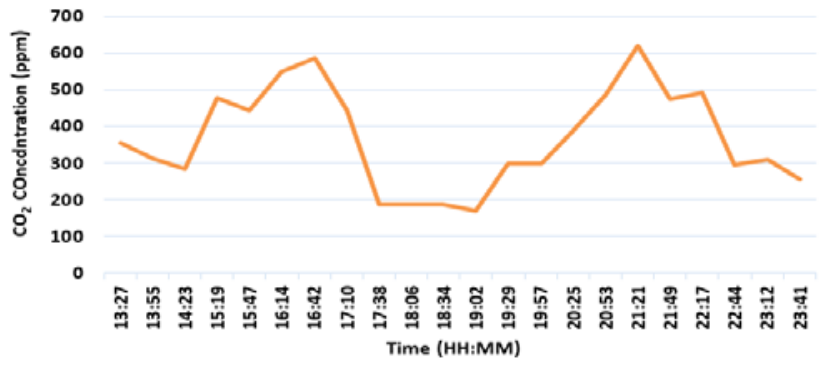

Fig. 20. $\mathrm{CO}_{2}$ Concentration.

[9] J. Navarro-Ortiz, S. Sendra, P. Almegeiras and, J.M. Lopez-Soler (2018). Integration of LoRaWAN and 4G/5G for the Industrial Internet of Things. IEEE Communications Magazine, 2018, vol. 56, no 2, p. 60-67.

[10] D. Ismail, M. Rahman, A. Saifullah,” Low-power wide-area networks: opportunities, challenges, and directions", In Proc. of the 19th Int. Conf. on Distributed Computing and Networking (Workshops ICDCN '18). Jan. 04 - 07, 2018. Varanasi (India).

[11] L. García, J. M. Jiménez, M. Taha, J. Lloret, "Wireless Technologies for IoT in Smart Cities,” Network Protocols and Algorithms 2018, vol. 10, no. 1, pp. 23-64.

[12] V. Perez-Garrancho, L. García, S. Sendra and, J. Lloret. "Mobile Low Cost system for Environmental Monitoring in Emergency Situations". In Proc. of the $7^{\text {th }}$ Int. Conf. on Ambient Computing, Applications, Services and Technologies (AMBIENT 2017), Barcelona (Spain). Nov.12 - 16, 2017. (pp. 12-16).

[13] M.Y. Hariyawan, A. Gunawan y E.H. Putra, "Wireless sensor network for forest fire detection”. Telkomnika, 2013, vol. 11, no. 3, pp. 563.

[14] L. Yu, N. Wang and, X. Meng, "Real-time forest fire detection with wireless sensor networks," In Proc. of the 2005 Int. Conf. on Wireless Communications, Networking and Mobile Computing, Sept. 26, 2005, Wuhan (China), (pp. 1214-1217)

[15] S. Abdullah, S. Bertalan, S. Masar, A. Coskun and, I. Kale, "A wireless sensor network for early forest fire detection and monitoring as a decision factor in the context of a complex integrated emergency response system," In proc. of the 2017 IEEE Workshop on Environmental, Energy, and Structural Monitoring Systems (EESMS 2017), July 24-25, 2017, Milan (Italy), (pp. 1-5).

[16] J. Lloret, M. Garcia, D. Bri, S. Sendra, "A Wireless Sensor Network Deployment for Rural and Forest Fire Detection and Verification", Sensors, 2009, vol. 9,no. 11, pp. 8722-874.

[17] G. Hristov, J. Raychev, D. Kinaneva and, P. Zahariev, "Emerging Methods for Early Detection of Forest Fires Using Unmanned Aerial Vehicles and Lorawan Sensor Networks," In proc. of the 28th EAEEIE Annual Conference (EAEEIE 2018), Sep. 26-28, 2018, Hafnarfjörður(Iceland), pp. 1-9.

[18] J. Lecina-Diaz, A. Alvarez and, J. Retana, "Extreme fire severity patterns in topographic, convective and wind-driven historical wildfires of Mediterranean pine forests”. PloS one, 2014, vol. 9, no. 1, e85127.

[19] A. B. Bomgni, G. B. Jagho Mdemaya, "A2CDC: Area Coverage, Connectivity and Data Collection in Wireless Sensor Networks", Network Protocols and Algorithms, 2018, vol 10, no. 4, pp. 20-34.

[20] P. Romero-Díaz, L. Garcia, S. Sendra, J. Navarro-Ortiz, "Performance of LoRaWAN Networks in Outdoor Scenarios", In Proc. of the 18th Int. Conf. on Networks (ICN 2019), March 24-28, 2019, Valencia (Spain). (Pp. 1-6). 